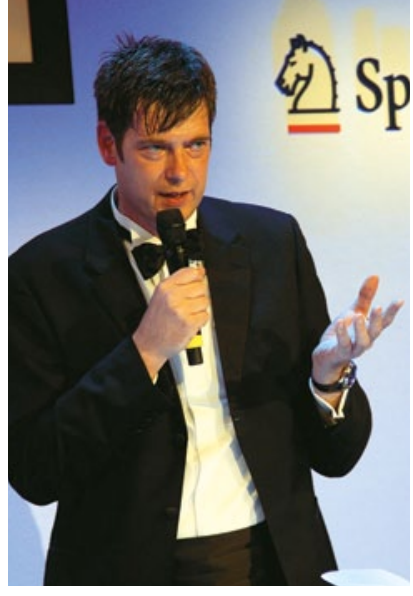

Harm van Maanen, EVP Springer Medizin, eröffnet die festliche Galenus-Gala in Berlin.

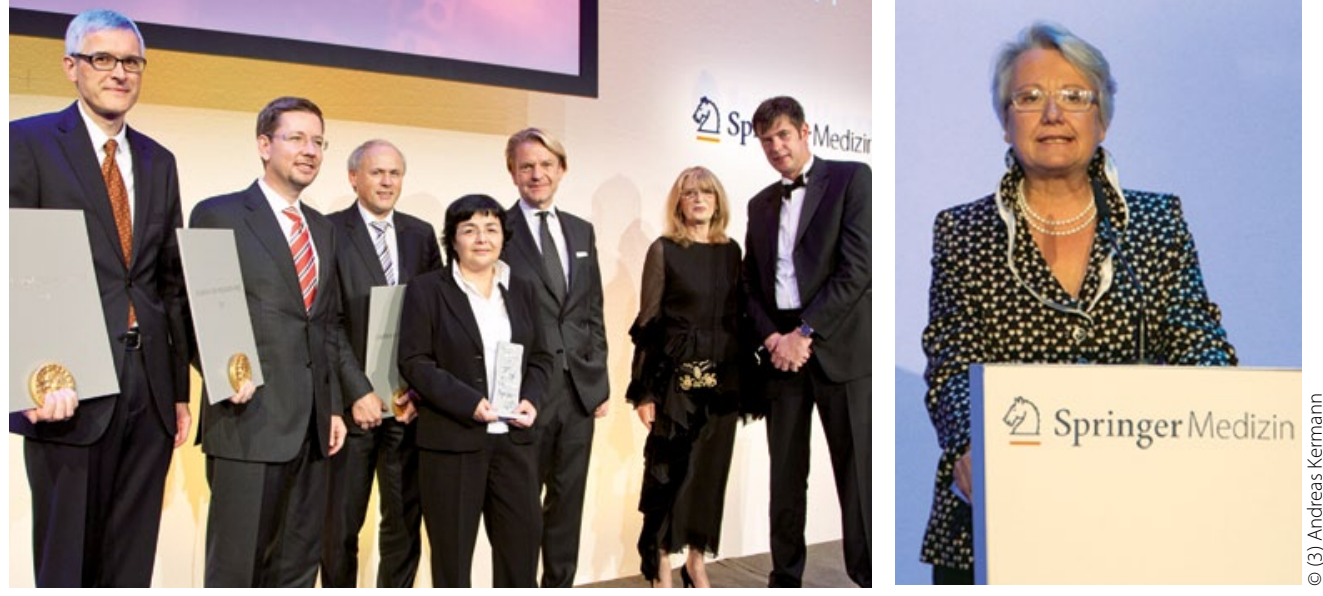

Die glücklichen Gewinner (v. I.): Prof. Wolfgang Kühn, Richard A. Paulson, Prof. Winand Lange, Jenny De la Torre, Prof. Alexander Ehlers. Florence Mehl und Harm van Maanen freuen sich mit ihnen.
Bundesforschungsministerin Prof. Annette Schavan hält die Laudatio zum Galenus-Preis.

\title{
Galenus-Preis und CharityAward von Springer Medizin verliehen
}

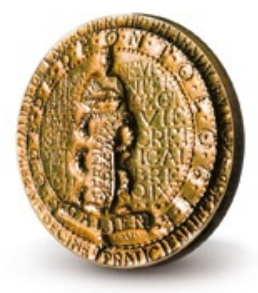

\section{Bei einer festlichen Gala in Berlin erhielten das Osteoporose-Präparat Denosumab (Prolia ${ }^{\oplus}$ ) sowie der Thrombopoetin-Rezeptor-Agonist Romiplostim (Nplate ${ }^{\oplus}$ ) den Galenus-Preis 2011. Mit dem CharityAward wurde die Berliner Ärztin Jenny De la Torre geehrt.}

— „In diesem Jahr war es schwierig, eine Entscheidung zu fällen", so der GalenusJury-Präsident und Kardiologe Prof. Erland Erdmann aus Köln bei der Bekanntgabe des Gewinners in der Kategorie Primary Care. Letztlich hatten die Jury-Mitglieder aber mit deutlicher Mehrheit entschieden, dass Denosumab von Amgen und GlaxoSmithKline den ersten Preis erhalten soll.

\section{Neues Wirkprinzip gegen \\ Osteoporose}

Denosumab zeichnet sich durch einen innovativen Wirkmechanismus aus: Es handelt sich um einen monoklonalen Antikörper, der den Knochenabbau gezielt verlangsamt. Ansatzpunkt des Medikamentes ist der sog. RANK-Ligand ein Protein, welches Reifung, Funktion und Überleben der Osteoklasten steuert.

In einer großen Doppelblindstudie mit 7808 postmenopausalen Frauen mit Osteoporose konnte Denosumab in einem Zeitraum von drei Jahren das Risiko für Wirbelfrakturen um $68 \%$ von $7,2 \%$ auf 2,3\% sowie das Risiko für Hüftfrakturen um $40 \%$ von $1,2 \%$ auf $0,7 \%$ senken. Außer bei postmenopausalen Frauen mit erhöhtem Frakturrisiko ist das Medikament auch zur Therapie bei Männern mit Prostatakarzinom und erhöhtem Frakturrisiko unter Hormonablation zugelassen.

\section{Erstes Medikament gegen Thrombozytopenie}

Der Gewinner in der Kategorie Specialist Care, Nplate ${ }^{\bullet}$ von Amgen, enthält den Wirkstoff Romiplostim. Der Thrombopoetin-Rezeptor-Agonist stimuliert die Thrombozytenbildung. In Studien über bis zu fünf Jahren erhöhte er die Zahl der Blutplättchen signifikant und dauerhaft bei $95 \%$ der Patienten auf Werte über 50000 pro Mikroliter Blut. „Das hat uns überzeugt", begründete Prof. Erdmann die Wahl der Jury. Indiziert ist Romiplostim zur Behandlung der chronischen immun-thrombozytopenischen Purpura ITP.

\section{Pathomechanismus von Nierenzysten entschlüsselt}

In der Kategorie Grundlagenforschung hat sich die Jury in diesem Jahr für eine nephrologische Arbeit entschieden: Gewinner ist die Arbeitsgruppe um Prof. Wolfgang Kühn vom Uniklinikum Freiburg. Kühn ist es mit Dr. Fruzsina Kotsis und Dr. Christopher Böhlke aus Freiburg gelungen, den molekularen Pathomechanismus der erblichen polyzystischen Nierenerkrankung zu entschlüsseln, wodurch sich Hoffnungen auf eine Therapie begründen.

\section{Engagement für Menschen im Abseits prämiert}

Zeitgleich mit dem Galenus-von-Pergamon-Preis für herausragende Forschungsleistungen wird seit einigen Jahren der CarityAward verliehen, der vorbildliche und selbstlose Initiativen in der Gesundheitsversorgung prämiert. Mit dem CharityAward 2011 wurde die Berliner Ärztin Jenny De la Torre ausgezeichnet. Seit 16 Jahren setzt sie sich für die Betreuung von Obdachlosen in Berlin ein und versorgt täglich bis zu 60 hilfsbedürftige Menschen. In Vertretung des Schirmherren des CharityAward, Bundesgesundheitsminister Daniel Bahr, überreichte die Parlamentarische Staatssekretärin Annette WidmannMauz den Preis, der mit einem Medienpaket im Wert von 100000 Euro und einem Barscheck über 50000 Euro dotiert ist. 